Volume 5 Nomor. 2, Oktober 2020

P-ISSN : 2541-1179, E-ISSN : 2581-1711

Ojs :http://journal.uin-alauddin.ac.id/index.php/instek/index

Email : instek@uin-alauddin.ac.id

\title{
ANALISIS TRANSFORMATOR DAYA BERDASARKAN \\ PENGUJIAN MINYAK TRAFO PADA RING MAIN UNIT (RMU) PSK 151 DI PT. PLN (PERSERO) UP3 CIKUPA
}

\author{
IRWANTO ${ }^{1}$, ROGA DINAR PRABUSTYA ${ }^{2}$ \\ ${ }^{1,2}$ Pendidikan Vokasional Teknik Elektro, Fakultas Keguruan dan Ilmu Pendidikan \\ Universitas Sultan Ageng Tirtayasa, Serang-Banten 42117, Indonesia \\ E-mail :1irwanto.ir@untirta.ac.id
}

\begin{abstract}
ABSTRAK
Energi listrik yang digunakan setiap hari berasal dari suatu tempat yang biasa kita kenal sebagai pembangkit listrik, yang kemudian di salurkan ke konsumen. Proses penyaluran ini disebut Sistem Distribusi. Metode penelitian yang digunakan dalam penulisan jurnal ini adalah metode penelitian kualitatif dengan pendekatan deskriptif. Teknik pengumpulan data yang digunakan pengamatan langsung, wawancara serta dokumentasi. Hasil penelitian yang didapat bahwa distribusi primer adalah jaringan distribusi dari transmisi yang diturunkan tegangannya di gardu induk menjadi tegangan menengah dengan nominal $20 \mathrm{KV}$ yang biasa disebut jaringan teganagn menengah. Untuk distribusi sekunder yaitu jaringan distribusi dari gardu distribusi ke pelanggan dengan klasifikasi tengan rendah. Proses Distribusi ini dikerjakan oleh PT. PLN (Persero) UP3 Cikupa dengan ruang lingkup distribusi area cikupa dan sekitarnya.
\end{abstract}

Kata Kunci: Energi listrik, UP3 Cikupa, Main Unit, PSK 151

\section{PENDAHULUAN}

Dalam era revolusi industri 5.0 ini kemajuan IPTEK telah berkembang sangat cepat, banyak aspek yang dimanfaatkan di bidang-bidang tertentu misalnya dalam bidang pendidikan, industri, transportasi, ekonomi, bisnis, bahkan keperluan rumah tangga yang sering diperlukan untuk kehidupan umat manusia. Dalam kehidupan manusia sangat membutuhkan energi listrik untuk menjalankan aktivitas-aktivitas pekerjaannya. Tentunya energi listrik yang digunakan setiap hari berasal dari suatu tempat yang biasa kita kenal sebagai pembangkit listrik, yang kemudian di salurkan ke konsumen. Proses penyaluran ini disebut sistem pendistribusian, sistem pendistribusian merupakan salah satu bagian terpenting dari suatu sistem ketenagaan listrik, bertujuan untuk dapat mengalirkan tenaga listrik dari sumber daya listrik yang lebih tinggi pada suatu pembangkit listrik. 
Volume 5 Nomor. 2, Oktober 2020

P-ISSN : 2541-1179, E-ISSN : 2581-1711

Ojs :http://journal.uin-alauddin.ac.id/index.php/instek/index

Email : instek@uin-alauddin.ac.id

Proses pendistribusian dapat dibagi menjadi dua bagian elemen terpenting yaitu pendistribusi primer dan pendistribusi sekunder. Pendistribusian primer merupakan suatu jaringan pendistribusian dari jarigan transmisi diturunkan tegangannya di gardu induk menjadi tegangan menengah dengan nominal $20 \mathrm{KV}$ yang dikenal sebutan jaringan teganagn menengah. Untuk pendistribusian sekunder yaitu jaringan distribusi dari Gardu Distribusi ke pelanggan dengan klasifikasi tengan rendah. Proses distribusi ini dikerjakan oleh PLN (Persero) UP3 Cikupa, dengan ruang lingkup distribusi area cikupa dan sekitarnya.

Dengan begitu penulis tertarik untuk mengamati tentang peralatan distribusi dan peralatan-peralatan yang digunakan dalam pendistribusian terutama pada bagian distribusi sekunder pada Peralatan Gardu Distribusi Ring Main Unit (RMU) PSK 151 Pada Sisten Distribusi Tenaga Listrik Di PT PLN (Persero) UP3 Cikupa. Dalam mengamati bidang Distribusi tersebut Penulis memilih tempat Praktik Industri yaitu PT PLN UP3 Cikupa, karena lokasinya yang dekat dengan tempat tinggal dan mempunyai kinerja dan prestasi yang bagus dalam beroprasi. Tujuan dari penelitian ini adalah: (1) mengetahui tentang Gardu distribusi di PT PLN UP3 Cikupa (2) mengetahui cara kerja Gardu Ring Main Unit PSK 151 di PT PLN UP3 Cikupa (3) memahami keterkaitan Gardu Ring Main Unit PSK 151 di PT PLN UP3 Cikupa pada sistem pendistribusian Cikupa.

Sistem pendistribusian yaitu suatu bagian dari sistem ketenagaan listrik, dengan bertujuan untuk dapat menyalurkan suatu ketenagaan listrik yang bersumber daya listrik yang lebih tinggi ke masyarakat. Adapun fungsi pendistribusian ketenagaan listrik yaitu (a) sebagai pembagian atau dapat menyalurkan tenaga listrik ke beberapa tempat (pelanggan) (b) sebagai sub-sistem untuk tenaga listrik yang langsung berhubungan dengan beberapa tempat. Jadi sistem pendistribusian adalah suatu bagian sangat penting dalam sistem ketenagaan listrik secara keseluruhan (Suhadi, 2008).

Dalam memudahkan dapat dilakukan pembagian atau pembatasan pada sistem penyaluran tenaga listrik yaitu: Daerah I untuk pembagkit, Daerah II untuk tempat penyaluran (transmission) tegangan tinggi HV, UHV, EHV, Daerah III 
Volume 5 Nomor. 2, Oktober 2020

P -ISSN : 2541-1179, E-ISSN : 2581-1711

Ojs :http://journal.uin-alauddin.ac.id/index.php/instek/index

Email : instek@uin-alauddin.ac.id

untuk distribusi primer, yang bertegangan menengah 20KV, Daerah IV untuk instalasi bertegangan rendah. Batasan-batasan ini, dapat porsi materi pada sistem pendistribusian daerah III dan daerah IV pada dasarnya dapat dikelasifikasikan menurut beberapa cara, tergantung dari segi apa kelasifikasi yang dibuat. Jadi demikian ruang lingkup mengenai jaringan pendistribusian (Suhadi, 2008).

\section{METODE PENELITIAN}

Metode penelitian yang digunakan adalah metode penelitian kualitatif dengan pendekatan deskriptif. Teknik pengumpulan data yaitu pengamatan secara langsung, wawancara serta dokumentasi. Pengamatan secara langsung merupakan bagian dalam pengumpulan data, pengamatan berati pengumpulan data secara langsung dari lapangan. Proses pengamatan dimulai dengan mengidentifikasi tempat yang hendak diteliti. Setelah tempat penelitian diidentifikasi, dilanjutkan dengan membuat pemetaan, sehingga diperoleh gambaran umum tentang sasaran penelitian yang dilakukan (Raco, 2005).

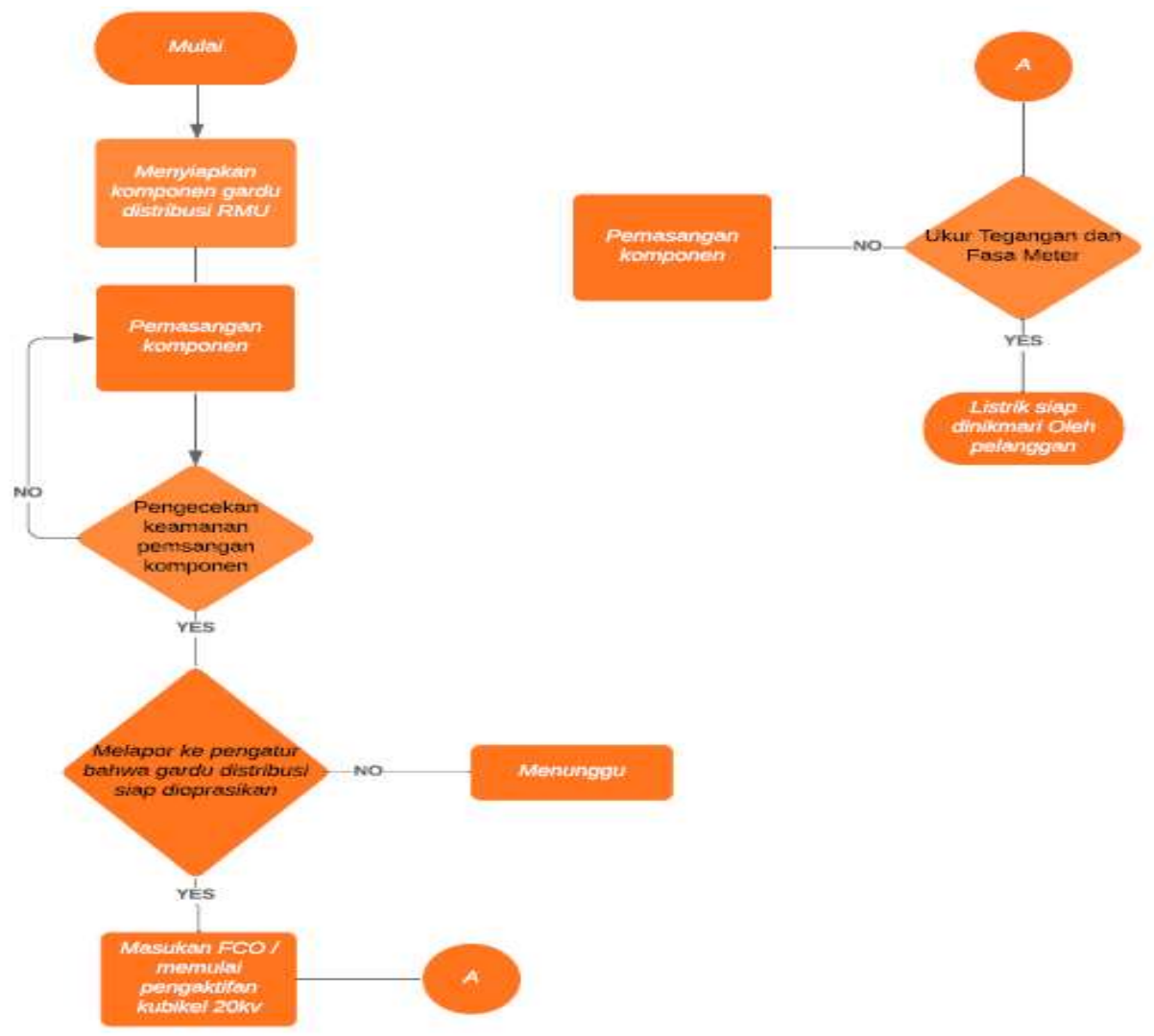

Gambar II.1 Flow Chart Penelitian 
Volume 5 Nomor. 2, Oktober 2020

P-ISSN : 2541-1179, E-ISSN : 2581-1711

Ojs :http://journal.uin-alauddin.ac.id/index.php/instek/index

Email : instek@uin-alauddin.ac.id

\section{III.HASIL DAN PEMBAHASAN}

\section{Analisis Yang Telah Dilakukan Gardu Distribusi Ring Main Unit (RMU) PSK 151}

Untuk menganalisis kondisi internal Transformator Daya 150KV AT04 KDL, maka perlu dilakukan interpretasi dari hasil pengujian DGA Minyak Trafo. Berikut ini merupakan data hasil pengujian DGA terhadap sample Minyak Transformator Daya 150KV AT04 PT. KDL yang diambil pada tanggal 31 Oktober 2019 yaitu saat dilakukan Predictive Maintenance (Annualy).

Tabel III.1. Hasil uji DGA

\begin{tabular}{|c|c|c|c|c|c|c|c|c|}
\hline \multicolumn{10}{|c|}{ GC DATA VALUES OF GASES ARE EXPRESSED IN PPM (PART PER MILLION) } \\
\hline \multirow{2}{*}{ Date } & $\begin{array}{c}\text { Hydrogen } \\
\left(\mathrm{H}_{2}\right)\end{array}$ & $\begin{array}{c}\text { Carbon } \\
\text { Dioxide } \\
\left(\mathrm{CO}_{2}\right)\end{array}$ & $\begin{array}{c}\text { Carbon } \\
\text { Monoxide } \\
(\mathrm{CO})\end{array}$ & $\begin{array}{c}\text { Ethylene } \\
\left(\mathrm{C}_{2} \mathrm{H}_{4}\right)\end{array}$ & $\begin{array}{c}\text { Ethane } \\
\left(\mathrm{C}_{2} \mathrm{H}_{6}\right)\end{array}$ & $\begin{array}{c}\text { Methane } \\
\left(\mathrm{CH}_{4}\right)\end{array}$ & $\begin{array}{c}\text { Acetylene } \\
\left(\mathrm{C}_{2} \mathrm{H}_{2}\right)\end{array}$ & TDGC \\
\cline { 2 - 10 } & $\mathbf{1 0 0}$ & $\mathbf{2 5 0 0}$ & $\mathbf{3 5 0}$ & $\mathbf{5 0}$ & $\mathbf{6 5}$ & $\mathbf{1 2 0}$ & $\mathbf{2 5}$ & $\mathbf{7 2 0}$ \\
\hline $\mathbf{3 1 / 1 0 / 1 9}$ & $\mathbf{3}$ & $\mathbf{2 4 3 7}$ & $\mathbf{5 3}$ & $\mathbf{5}$ & $\mathbf{3}$ & $\mathbf{5}$ & $\mathbf{0}$ & $\mathbf{6 9}$ \\
\hline
\end{tabular}

Dari Tabel III.1 di atas dapat dijelaskan bahwa kondisi Transformator Daya

AT04 berada dalam Kondisi 1 karena nilai konsentrasi TDCG berada dalam batas normal (TDCG < 720). Kondisi 1 mengindikasikan bahwa Transformator beroperasi normal, akantetapi masih perlu dilakukan pemantauan kondisi gas-gas tersebut. Apa lagi bila dilihat dari kandungan gas Karbon dioksida $\left(\mathrm{CO}_{2}\right)$ yang hampir mendekati batas Kondisi 1 yaitu 2437 (batas normal 2500). Hal ini perlu diperhatikan dan dianalisis lebih lanjut karena apabila dibiarkan saja maka akan menyebabkan kegagalanpada Trafo. Untuk menganalisis lebih lanjut maka diperlukan metode interpretasi terhadap gas-gas terlarut ini. Metode interpretasi yang digunakan pada pembahasan ini adalah metode Key Gases, Doernenburg Ratio, IEC Method dan Duval's Triangel. 
Volume 5 Nomor. 2, Oktober 2020

P -ISSN : 2541-1179, E-ISSN : 2581-1711

Ojs :http://journal.uin-alauddin.ac.id/index.php/instek/index

Email : instek@uin-alauddin.ac.id

Analisa Key Gas Method

Untuk menggunakan metode ini diharuskan untuk mengubah konsentrasi gas yang semula dalam bentuk PPM (Part Per Million) menjadi bentuk Persentase (\%), hal ini dikarenakan untuk memudahkan dalam proses penganalisisan. Dibawah ini terdapat grafik Key Gases yang menunjukkan Persentase konsentrasi gas yang tekandung dalam Transformator AT04 (pengujian tanggal 31 Oktober 2019).

Tabel III.2. Konsentrasi key gasses

\begin{tabular}{|c|c|c|}
\hline Nama Gas & Konsentrasi & Persentase (\%) \\
\hline $\mathrm{CO}$ & 53 & 76.81 \\
\hline $\mathrm{H}_{2}$ & 3 & 4.34 \\
\hline $\mathrm{CH}_{4}$ & 5 & 7.24 \\
\hline $\mathrm{C}_{2} \mathrm{H}_{6}$ & 3 & 4.34 \\
\hline $\mathrm{C}_{2} \mathrm{H}_{4}$ & 5 & 7.24 \\
\hline $\mathrm{C}_{2} \mathrm{H}_{2}$ & 0 & 0 \\
\hline $\mathrm{TDCG}$ & 69 & 100 \\
\hline
\end{tabular}

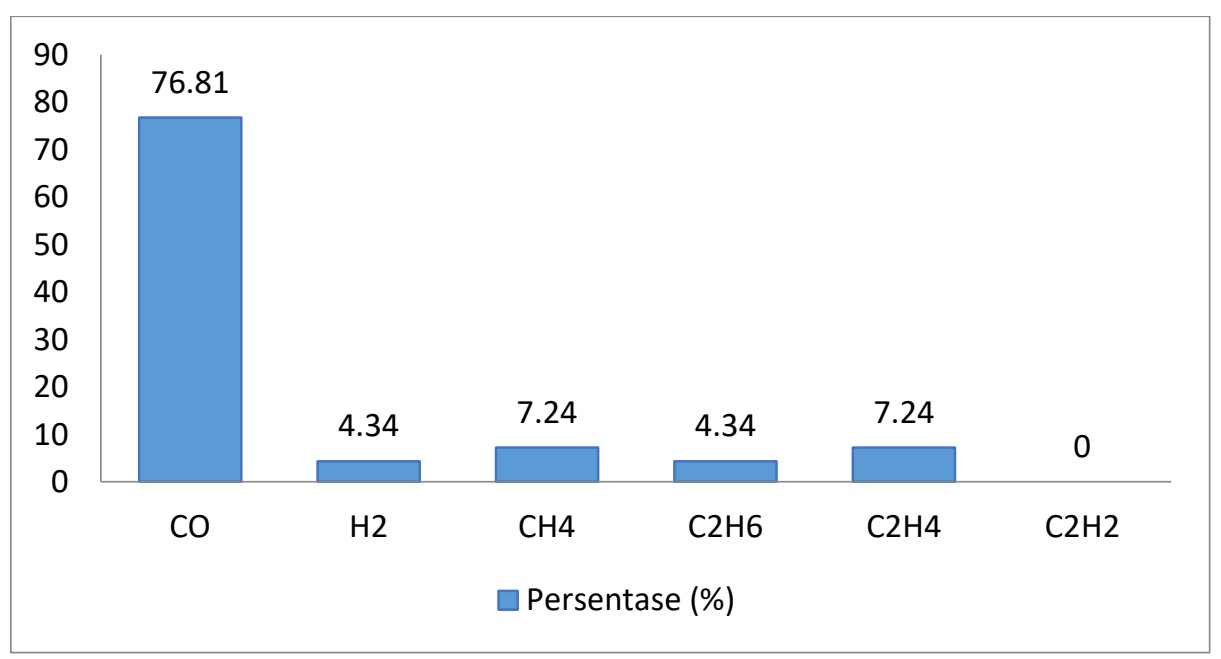

Gambar III.1. Persentase key gasses

Dari Gambar di atas, dapat diketahui gas yang paling dominan adalah gas Karbon monoksida (CO). Berdasarkan grafik Key Gases dengan Key Gases Method, menunjukan bahwa ada kemiripan dan kecocokan dengan pola grafik Key Gases (Grafik 1) karena gas yang paling signifikan adalah gas karbon monoksida. 
Volume 5 Nomor. 2, Oktober 2020

P -ISSN : 2541-1179, E-ISSN : 2581-1711

Ojs :http://journal.uin-alauddin.ac.id/index.php/instek/index

Email : instek@uin-alauddin.ac.id

Gas karbon monoksida (CO) merupakan Key Gases untuk mengindikasikan panas berlebih pada isolasi kertas (Overheated Celullose).

\section{Analisis Doernenburg Ratio Method}

Syarat yang dibutuhkan untuk menggunakan analisa rasio doernenburg adalah: (1) Minimal satu konsentrasi gas $\left(\mathrm{H}_{2}, \mathrm{CH}_{4}, \mathrm{C}_{2} \mathrm{H}_{2}, \mathrm{C}_{2} \mathrm{H}_{4}, \mathrm{C}_{2} \mathrm{H}_{6}\right)$ melebihi dua kali L1. (2) Salah satu dari dua gas lain $\left(\mathrm{C}_{2} \mathrm{H}_{6}\right.$ dan $\left.\mathrm{CO}\right)$ melebihi batas L1. (3) Minimal satu gas di empat ratio (R1, R2, R3, dan R4) melebihi limit L1. Batas konsentrasi L1 tepat sama dengan batas kondisi 1 konsentrasi gas terlarut pada. Namun syarat ini tidak disarankan karena diperlukan nilai gas yang signifikan sebagai pertimbangan bahwa benar-benar terjadi fault pada trasnformator sehingga dapat menunjang validity dari analisa kegagalan transformator. Berikut Tabel 3 perhitungan Rasio Doernenburg:

Tabel III.3. Rasio doernenburg uji DGA

\begin{tabular}{|c|c|c|c|}
\hline \multicolumn{2}{|c|}{ Rasio Doernenburg } & AT04 & Keterangan \\
\hline Ratio 1(R1) & $\mathrm{CH}_{4} / \mathrm{H}_{2}$ & 1,66 & Tidak dapat digunakan \\
\hline Ratio 2(R2) & $\mathrm{C}_{2} \mathrm{H}_{2} / \mathrm{C}_{2} \mathrm{H}_{4}$ & 0 & Tidak dapat digunakan \\
\hline Ratio 3(R3) & $\mathrm{C}_{2} \mathrm{H}_{2} / \mathrm{CH}_{4}$ & 0 & Tidak dapat digunakan \\
\hline Ratio 4(R4) & $\mathrm{C}_{2} \mathrm{H}_{6} / \mathrm{C}_{2} \mathrm{H}_{2}$ & 0 & Tidak dapat digunakan \\
\hline
\end{tabular}

Data sampel DGA yang telah dibuat kedalam tabel diatas menunjukan bahwa syarat-syarat di atas tidak terpenuhi, sehingga analisa Doernenburg tidak bisa diterapkan dan dianalisa lebih lanjut.

\section{Analisis IEC Ratio Method}

Analisa ini merupakan revisi Roger's Ratio Method yang merupakan hasil dari gabungan pengalaman indstri, tes laboratorium, dan penilaian teoritis oleh para ahli dimana metode tercantum dalam standar IEC (IEC 599-1996). Analisa ini hanya menggunakan 3 jenis Rasio yaitu Rasio 1, Rasio 2 dan Rasio 5. Rasio 3 
Volume 5 Nomor. 2, Oktober 2020

P -ISSN : 2541-1179, E-ISSN : 2581-1711

Ojs :http://journal.uin-alauddin.ac.id/index.php/instek/index

Email : instek@uin-alauddin.ac.id

tidaklah digunakan hal tersebut dikarenakan Rasio 3 hanya mampu mengindikasi kisaran suhu dekomposisi yang terbatas. Berikut adalah hasil perhitungan yang telah penulis lakukan sesuai dengan data Hasil Uji DGA:

Tabel III.4. Hasil perbandingan IEC ratio method

\begin{tabular}{|c|c|c|c|}
\hline \multicolumn{2}{|c|}{ Roger's Ratio } & Hasil & Case \\
\cline { 1 - 2 } Ratio 1(R1) & $\mathrm{CH}_{4} / \mathrm{H}_{2}$ & 1,02 & $\begin{array}{c}\text { Thermal Fault } \\
\text { of Medium } \\
\text { Themperature } \\
300^{\circ} \text { - } 700^{\circ} \mathrm{C}\end{array}$ \\
\hline Ratio 2(R2) & $\mathrm{C}_{2} \mathrm{H}_{2} / \mathrm{C}_{2} \mathrm{H}_{4}$ & 0 & \\
\cline { 1 - 3 } Ratio 5(R5) & $\mathrm{C}_{2} \mathrm{H}_{4} / \mathrm{C}_{2} \mathrm{H}_{6}$ & 1,6 & \\
\hline
\end{tabular}

Sama seperti pada Roger's Ratio, IEC Ratio Method juga menggunakan Range dan Kode Definisi. Hasil yang didapatkan dari perhitungan rasio 1, rasio 2, dan rasio 5 akan dicocokan dengan Kode Range of Gas Ratio pada Tabel III.4. Fungsi Range disini adalah untuk menemukan Kode Definisinya. Kode Definisi yang didapatkan yaitu R1=2, R2=0, dan R5=1. Berdasarkan Kode Definisi tersebut ditemukan kecocokan dengan Tabel III.5 yaitu tabel Klarifikasi Kegagalan Transformator.Dan berdasarkan tabel tersebut dapat diketahui jenis kegagalannya, yaituThermal Fault of Medium Themperature $300^{\circ}-700^{\circ} \mathrm{C}$. Metode ini mendukung hasil analisa Key Gases yang mendiagnosis penyebab Kegagalan pada Transformator adalah akibat Overheated Cellulose.Akibat Overheated menyebabkan penguraian pada isolasi kertas.

\section{Analisa Duval's Triangel}

Untuk memastikan kesimpulan sementara yang disebutkan di atas, ada baiknya digunakan analisa yang menurut beberapa sumber merupakan metode analisa yang paling banyak prosentase kebenarannya. Analisa selanjutnya adalah analisa Segitiga Duval yang merupakan perkembangan metode yang sudah ada. Metode ini tercantum dalam IEC 60599 Ratio Method dan IECTC10 databases. Metode analisa ini menggunakan konsentrasi gas $\left(\mathrm{CH}_{4}, \mathrm{C}_{2} \mathrm{H}_{2}\right.$, dan $\left.\mathrm{C}_{2} \mathrm{H}_{4}\right)$ yang berhubungan dengan Key Gases peningkatan level energi pembentukan gas. Enam jenis kegagalan ditambah satu kegagalan kombinasi yang dapat diindikasikan oleh 
Volume 5 Nomor. 2, Oktober 2020

P -ISSN : 2541-1179, E-ISSN : 2581-1711

Ojs :http://journal.uin-alauddin.ac.id/index.php/instek/index

Email : instek@uin-alauddin.ac.id

metode ini. Cara menggunakan metode segitiga duval adalah dengan menggambar tiga titik koordinat yang merupakan persen (\%) relatif tiga konsentrasi Key Gases tersebut pada Segitiga Duval yang kemudian dari ketiga titik tersebut ditarik garis sampai ketiga garis tersebut saling berpotongan. Titik persimpangan atau intersection dari ketiga garis tersebut merupakan indikasi kegagalan yang terjadi pada transformator.

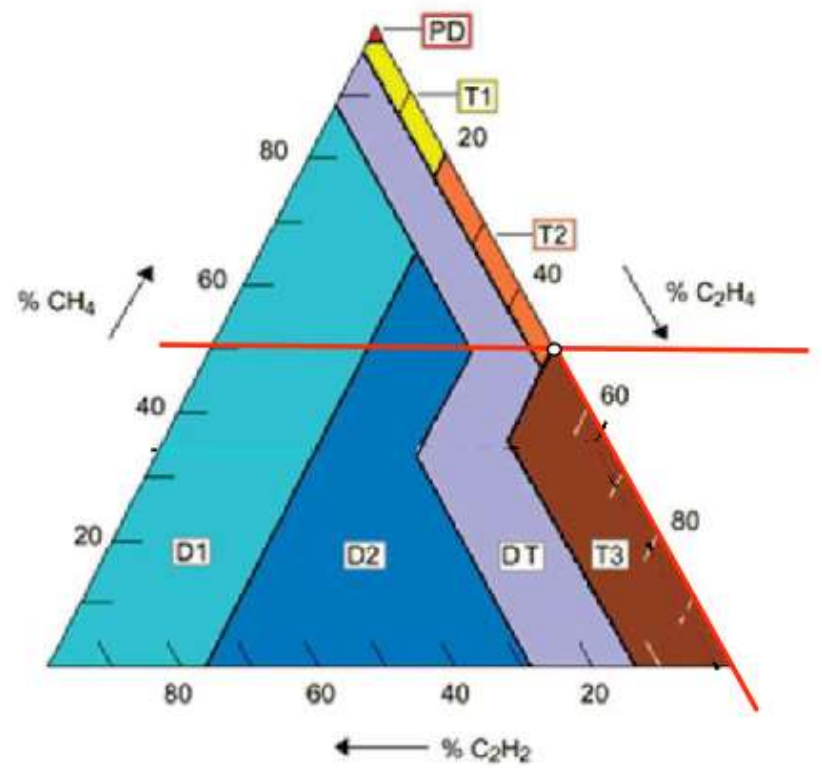

Gambar III.2. Hasil Uji DGA Duval Triangel

Diketahui:

$$
\begin{aligned}
& \mathrm{CH}_{4}=5 \mathrm{ppm} \\
& \mathrm{C}_{2} \mathrm{H}_{2}=0 \mathrm{ppm} \\
& \mathrm{C}_{2} \mathrm{H}_{4}=5 \mathrm{ppm} \\
& \text { Total } 10 \mathrm{ppm}
\end{aligned}+
$$

\section{Persen relatif \% tiap gas:}

$$
\begin{aligned}
& \text { Persen relatif } \% \mathrm{CH}_{4}=\frac{5}{10} \times 100=50 \% \\
& \text { Persen relatif } \% \mathrm{C}_{2} \mathrm{H}_{2}=\frac{0}{10} \times 100=0 \% \\
& \text { Persen relatif } \% \mathrm{C}_{2} \mathrm{H}_{4}=\frac{5}{10} \times 100=50 \%
\end{aligned}
$$

Titik persimpangan berada di zona T3 yang artinya Segitiga Duval mengindikasikan bahwa penyebab kegagalan yang terjadi pada Transformator 
Volume 5 Nomor. 2, Oktober 2020

P -ISSN : 2541-1179, E-ISSN : 2581-1711

Ojs :http://journal.uin-alauddin.ac.id/index.php/instek/index

Email : instek@uin-alauddin.ac.id

Daya AT04 merupakan kegagalan akibat suhu lebih dari $700^{\circ} \mathrm{C}$. Jenis kegagalan yang direkomendasikan oleh Metode Segitiga Duval mendukung dan memiliki persamaan dengan analisa Roger's Ratio Method dan Key Gas Method yakni Transformator Daya AT04 akibat overheat atau pengaruh termal stress yang tinggi.

\section{IV.KESIMPULAN}

1. Cara kerja gardu ring main unit berpusat pada kubikel, terdapat kubikel incoming, kubikel outgoing, dan kubikel trafo, kubikel incoming berfungsi sebagai sumber tegangan $20 \mathrm{KV}$ dari gardu induk, kubikel outgoing berfungsi untuk meneruskan teganagn $20 \mathrm{KV}$ tersebut ke gardu distribusi selanjutnya, dan kubikel trafo yang nantinya akan mengarah ke trafo yang kemudian diturunkan tegangannya menjadi 220/380KV dan disalurkan ke pelanggan .

2. Penyebab kegagalan yang terjadi pada Transformator Daya AT04 merupakan kegagalan akibat suhu lebih dari $700^{\circ} \mathrm{C}$. Jenis kegagalan yang direkomendasikan oleh Metode Segitiga Duval mendukung dan memiliki persamaan dengan analisa Roger's Ratio Method dan Key Gas Method yakni Transformator Daya AT04 akibat overheat atau pengaruh termal stress yang tinggi. 
Volume 5 Nomor. 2, Oktober 2020

P -ISSN : 2541-1179, E-ISSN : 2581-1711

Ojs :http://journal.uin-alauddin.ac.id/index.php/instek/index

Email : instek@uin-alauddin.ac.id

\section{DAFTAR PUSTAKA}

Choirur, R. O. P. (2015). Manajemen Gangguan Jaringan Distribusi 20 kV Kota Surabaya berbasis Geographic Infor-mation System (GIS) menggunakan Metode Algoritma Genetika. Jurnal Teknik ITS, B-52.

Dasman. (2017). Evaluasi Keandalan Sistem Distribusi 20 KV Menggunakan Metode Saidi dan Saifi di PT. PLN (PERSERO) Rayon Lubuk Alung Tahun 2015. Jurnal Teknik Elektro ITP, 171.

I Wayan Sudiartha, I. P. (2016). Manajemen Trafo Distribusi 20 KV Antar Gardu BL031 dan BL033 Penyulang Liligundi Dengan Menggunakan Simulasi Program Etap. Jurnal Logic, 166-168.

Jeandy, F. \&. (2016). Analisa Gangguan Hubung Singkat Saluran Kabel Bawah Tanah Te-gangan 20 kV Penyulang SL 3 GI Teling Manado. E-Journal Teknik Elektro dan Komputer, 46-47.

PLN Operasi \& Pemeliharaan Jaringan Distribusi. (1995).

Rochman, C. (2015). Manajemen Gangguan Jaringan Distribusi $20 \mathrm{kV}$ Kota Surabaya berbasis Geographic Information System (GIS) menggunakan Metode Algoritma Genetika. Jurnal Teknik ITS, B-52.

Suhadi. (2008). Teknik Distribusi Tenaga Listrik. Jakarta: Direktorat Pembinaan SMK, Jakarta, Indonesia.

Suswanto, D. (2009). Sistem Distribusi Tenaga Listrik Jaringan Distribusi Bawah Tanah. Padang: Universitas Negeri Padang.

Syufrizal, R. M. (2014). Jaringan Distribusi Tenaga Listrik. Jakarta: Kementrian Pen-didikan Dasar Menengah dan Kebudayaan Republik Indonesia.

Tanjung, A. (2012). Analisis Sistem Distribusi 20KV Untuk Memperbaiki Kinerja dan Keandalan Sistem Distribusi Menggunakan Electrical Transient Analisys Program. Seminar Nasional Teknologi Informasi Komunikasi dan Industri (SNTIKI), 2-5. 